\title{
ABSTRAK \\ PENGARUH PENDIDIKAN KESEHATAN DENGAN MEDIA LEAFLET TERHADAP PENGETAHUAN IBU TENTANG PENATALAKSANAAN ISPA PADA BALITA DI PUSKESMAS MAMBI KABUPATEN MAMASA
}

Andi Mayasari Usman ${ }^{1}$, Andan Firmansyah ${ }^{2}$, Ridwanca $^{3}$, Eko Firmansyah $^{4}$

$$
(\mathrm{xv}+84 \text { halaman }+9 \text { Tabel }+6 \text { Lampiran })
$$

Latar Belakang : Tercapainya keluarga sehat dilandasi pengetahuan yang baik dapat menimbulkan kesadaran diri untuk memelihara lingkungan, mencegah penyakit dan mempertahankan kesehatan. Keluarga dapat menciptakan lingkungan yang sehat untuk anggota keluarganya sehingga dapat mencegah berbagai macam penyakit lingkungan erat kaitannya dengan angka kejadian penyakit menular, terutama Infeksi Saluran Pernapasan Akut (ISPA).

Tujuan penelitian : Untuk mengetahui pengaruh pendidikan kesehatan dengan media leaflet terhadap pengetahuan ibu tentang penatalaksanaan ISPA pada balita di Puskesmas Mambi Kabupaten Mamasa.

Metode penelitian : Desain penelitian yang digunakan adalah Desain PreExperimental dengan rancangan One Group Pre-Test Post-Test Design. Populasi dalam penelitian ini adalah ibu memiliki balita ISPA yang membawa balitanya kepuskesmas. Sampel penelitian ini sebanyak 20 ibu yang diambil dengan tehnik Purposive Sampling. Alat ukur yang digunakan adalah kusioner.Data diolah secara univariat dan bivariate dengan menggunakan uji statistik Wilcoxondengan tingkat kemaknaan $\alpha=0.05$.

Hasil penelitian:Dari hasil yang didapatkan, disimpulkan bahwa ada pengaruh yang signifikan terhadap perubahan tingkat pengetahuan ibu sebelum dan sesudah pemberian pendidikan kesehatan dengan menggunakan media leaflet tentang penatalaksanaan ISPA dengan $p$-Value $=(p 0.000<0.05)$.

Kesimpulan:Dari hasil uji statistik Wilcoxondidapatkan, dapat disimpulkan bahwa ada pengaruh yang signifikan terhadap perubahan tingkat pengetahuan ibu sebelum dan sesudah pemberian pendidikan kesehatan dengan menggunakan media leaflet tentang penatalaksanaan ISPA.

Kata kunci :ISPA, Balita, Pengetahuan, Pendidikan Kesehatan Daftar Pustaka : 17Buku dari Tahun 2007-2017, 2 jurnal 


\title{
ABSTRACT \\ THE EFFECT OF HEALTH EDUCATION WITH LEAFLET MEDIA ON MOTHER KNOWLEDGE ON MANAGEMENT ARI IN TODDLERS IN MAMBI HEALTH CENTERMAMASA REGENCY
}

\author{
Andi Mayasari Usman ${ }^{1}$, Andan Firmansyah ${ }^{2}$, Ridwanca ${ }^{3}$, Eko Firmansyah ${ }^{4}$ \\ (xvi +84 pages +9 Table +6 Attachments $)$
}

Background: Achieving a healthy family based on good knowledge can lead to self awareness to preserve the environment, prevent disease and maintain health. Families can create a healthy environment for their family members so as to prevent various environmental diseases closely related to the incidence of infectious diseases, especially Acute Respiratory Infections (ARI).

Objective: To know the effect of health education with media leaflet to mother knowledge about management of ARI in toddler at Mambi District Health Center Mamasa.

Research Method: The research design used was Pre-Experimental Design with One Group Pre-Test Post-Test Design design. Population in this research is mother have toddler ISPA carrying balitanya kepuskesmas. Samples of this study were 20 mothers taken with Purposive Sampling technique. The measuring tool used is kusioner. The data were processed by univariate and bivariate using Wilcoxon statistic test with significance level $\alpha=0.05$.

Result of research: From the results obtained, it is concluded that there is a significant effect on the change of knowledge level of mother before and after giving of health education by using media leaflet about management of ISPA with $\mathrm{p}$-Value $=($ p $0.000<0.05)$.

Conclusion: From Wilcoxon statistic test results obtained, it can be concluded that there is a significant effect on the change of knowledge level of mother before and after giving of health education by using media leaflet about management of ARI.

Keywords : ARI, Toddler, Knowledge, Health Education

Bibliography : 17 Books from 2007-2017, 2 journals

PENDAHULUAN

Latar Belakang

Indonesia sebagai salah satu negara yang menanda tangani Tujuan Pembangunan
Millenium Developmen Goals (MDGs) berkomitmen mewujudkan peningkatan kualitas sumber daya manusia dan kualitas hidup yang lebih 
baik pada tahun 2015. Dari 8 (delapan) agenda pencapaian MDGs, salah satunya adalah menurunkan angka kematian balita 2/3 dari tahun 19902015(Junfeng, Zheng, \& Hengnian, 2015).

Bayi dan balita merupakan kelompok masyarakat yang rentan untuk terserang berbagai penyakit khususnya penyakit infeksi.Masa balita merupakan masa yang sangat peka terhadap lingkungan dan masa ini sangat pendek serta tidak dapat diulangi lagi maka masa balita disebut juga sebagai "masa keemasan" (golden period) dan "masa kritis" (critical period). Pertumbuhan dasar yang berlangsung pada masa bayi dan balita akan mempengaruhi dan menentukan perkembangan anak selanjutnya. Oleh sebab itu, kelompok ini harus mendapat perlindungan untuk mencegah terjadinya penyakit yang dapat mengakibatkan pertumbuhan dan perkembangan menjadi terganggu atau bahkan dapat menimbulkan kematian. Salah satu penyebab kematian tertinggi pada bayi dan balita adalah akibat penyakit infeksi saluran pernapasan akut (ISPA) (Junfeng et al., 2015).

ISPA merupakan singkatan dari Infeksi Pernafasan Saluran Akut. Infeksi Saluran Pernafasan Akut (ISPA) adalah infeksi akut yang menyerang salah satu bagian / lebih dari saluran napas mulai dari hidung sampai alveoli termasuk adneksanya (sinus, rongga telinga tengah, pleura)(Ilmiah, Batanghari, \& Vol, 2017).

WHO menyatakan pola penyebaran ISPA yang utama adalah melalui droplet yang keluar dari hidung atau mulut penderita saat mereka batuk atau bersin.ISPA banyak menyerang balita dan usia sekolah dasar yang berusia kurang dari 15 tahun, karena pada kelompok usia tersebut mereka belum memiliki sistem kekebalan tubuh seperti yang dimiliki orang dewasa. Selain itu, anakanak pada usia ini sering melakukan aktivitas di luar ruangan sehingga sering terpapar dengan debu yang dapat menyebabkan penyakit ISPA.

Tercapainya keluarga sehat yang dilandasi pengetahuan yang baik dapat menimbulkan kesadaran diri untuk memelihara lingkungan, mencegah penyakit dan mempertahankan kesehatan. Keluarga dapat menciptakan lingkungan yang sehat untuk anggota keluarganya sehingga dapat mencegah berbagai macam penyakit lingkungan erat kaitannya dengan angka kejadian penyakit menular, terutama Infeksi Saluran Pernapasan Akut (ISPA) (Utari, Novayelinda, \& Arneliwati, 2011). 
Menurut Notoatmodjo (2012) yang dikutip dalam (Ilmiah et al., 2017), pengetahuan adalah hasil dari penginderaan manusia atau hasil dari tahu seseorang terhadap objek melalui indera yang dimilikinya. Pendidikan Kesehatan sebagai bagian dari kesehatan masyarakat, berfungsi sebagai media atau sarana untuk menyediakan kondisi sosiopsikologi sedemikian rupa sehingga individu atau masyarakat berperilaku sesuai dengan norma-norma hidup sehat, dengan perkataan lain pendidikan kesehatan bertujuan mengubah pengetahuan, sikap dan tindakan individu atau masyarakat sehingga sesuai dengan norma-norma hidup sehat, pendidikan akan berpengaruh pada perilaku kesehatan, selanjutnya perilaku kesehatan akan berpengaruh pada meningkatnya indikator kesehatan masyarakat (outcome) pendidikan kesehatan.

Salah satu upaya yang dapat dilakukan untuk meningkatkan pengetahuan ibu tentang Penatalaksanaan ISPA adalah dengan pemberian pendidikan

kesehatan.Peningkatan

pengetahuan ini sangat dibutuhkan oleh ibu agar dapat memahami dalam penatalaksanaan dan pencegahan ISPA.Pendidikan kesehatan merupakan gambaran penting dan bagian dari peran perawat yang profesional dalam upaya promosi kesehatan dan pencegahan penyakit (preventif) (Fitriani, 2011).

Berkaitan dengan usaha meningkatkan pengetahuan ibu tentang ISPA melalui pendidikan kesehatan, media pendidikan kesehatan sangat berperan penting karena media tersebut akan mempermudah penerimaan pesan kesehatan bagi masyarakat. Media pendidikan kesehatan adalah semua sarana atau upaya untuk menampilkan pesan informasi yang ingin disampaikan oleh komunikator sehingga sasaran dapat meningkat pengetahuannya yang akhirnya diharapkan dan berubah perilakunya kearah positif terhadap kesehatan (Ilmiah et al., 2017).

Perilaku ibu menjadi sangat penting karena didalam merawat balitanya, ibu sering kali berperan sebagai pelaksana dan pengambil keputusan dan pengasuhan balita yaitu dalam hal memberikan makan, perawatan, kesehatan dan penyakit. Dengan demikian bila perilaku ibu baik dalam pengasuhan makanan dapat mencegah dan memberikan pertolongan pertama pada anak balita yang mengalami ISPA dengan baik (Silviana, 2014).

Sejalan dengan penelitian Tina Yuli Fatmawati 2016 
tentang Pengaruh pendidikan kesehatan dengan Media Leaflet terhadap Pengetahuan Ibu tentang penatalaksanaan ISPA pada balita di Posyandu Bambu Kuning, didapatkan hasil sebelum dan sesudah diberikan pendidikan kesehatan diperoleh nilai $p$-value $=0,00<0,05$ dengan selisih nilai mean -2.35 . Hal ini menunjukkan ada pengaruh yang signifikan antara pengetahuan responden sebelum dengan setelah diberikan pendidikan kesehatan (Ilmiah et al., 2017).

Dari berbagai media atau alat bantu pendidikan, leaflet merupakan media yang paling banyak dan sering digunakan oleh petugas kesehatan untuk menyampaikan informasi saat pendidikan kesehatan, karena leaflet berbentuk lembaran yang dilipat dan mudah dibawa kemana saja sehingga jika seseorang lupa apa yang sudah disampaikan maka bisa membacanya di leaflet (Notoatmodjo, 2011).

ISPA merupakan penyakit yang sering terjadi pada anak. Insidens menurut kelompok umur balita diperkirakan 0,29 episode/tahun di negara berkembang dan 0,05 episode/tahun di negara maju. Kasus terbanyak terjadi di India (43 Juta), China (21 Juta) dan Pakistan (10 Juta) dan Bangladesh, Indonesia dan Nigeria masing-masing 6 juta
Prevalensi ISPA pada balita di Indonesia sebanyak 25,0\% dengan karakteristik tertinggi terjadi pada kelompok umur 1-4 tahun (25,8\%) (Riskesdas, 2013).

Berdasarkan data dan informasi kesehatan profil kesehatan Indonesia tahun 2016, jumlah kasus pneumonia pada balita menurut provinsi dan kelompok umur tahun 2016 dari 34 provinsi di Indonesia sebanyak 503.738( $57.84 \%$ ). Terkhusus pada provinsi Sulawesi Barat temuan kasus sebanyak 2.252 balita(46.66\%) (Kelompok umur <1 tahun sebanyak 721 balita dan kelompok umur 1-4 tahun sebanyak 1.531balita ) dengan kasus kematian balita berjumlah 4 balita(Kementerian Kesehatan RI, 2017).

Berdasarkan laporan bidang pencegahan dan pengendalian penyakit dari dinas kesehatan kabupaten/kota di Provinsi Sulawesi Barat tahun 2015, kasus pneumonia mengalami peningkatan yang cukup selama 3 Tahun terakhir. Pada tahun 2014 kasus pneumonia menunjukkan adanya kecenderungan peningkatan dari 1371 kasus pada tahun 2013 menjadi 1382 kasus pada tahun 2014 dan meningkat lagi pada tahun 2015 menjadi 1625 kasus (Dinkes Prov. Sulawesi Barat, 2016). 
Di Kabupaten Mamasa pada tahun 2016berdasarkan laporan dari Bidang Pelayanan Kesehatan, Dinas Kesehatan Kabupaten

Mamasa.menunjukkan bahwa jumlah kesakitan110.595 penderita. Adapun penyakit dengan jumlah penderita terbanyak dari urutansepuluh besar penyakit adalah Infeksi Akut Lain pada Saluran pernafasanbagian atas sebesar 29.261penderita, sedangkan yang paling rendahadalah Penyakit kulit infeksi 3.668penderita. Pola penyakit dapat berubahdari tahun ke tahun tergantung pada beberapa faktor antara lain seperti asupangizi masyarakat, pendidikan/pengetahuan

masyarakat serta dipengaruhipula oleh adanya perubahan iklim yang tidak menentu dan lain sebagainya(Dinkes Mamasa, 2016).

Berdasarkan data dari Puskesmas Mambi Kabupaten Mamasa pada tahun 2014, didapatkan jumlah kasus ISPA sebanyak $3.686(36,01 \%)$ kasus, menurun pada tahun 2015

\section{METODE PENELITIAN}

\section{DesainPenelitian}

Agar penelitian dapat berjalan sebagaimana mestinya, rancangan penelitian harus disusun dan ditentukan sebelum dengan jumlah kasus ISPA sebanyak $3.010(29,40 \%)$ kasus dan meningkat pada tahun 2016 dengan jumlah kasus ISPA sebanyak 3.540(33,6\%) kasus (Profil Penyakit Puskesmas Mambi, 2016).

Berdasarkanstudi

pendahuluan yang telah dilakukan diPuskesmas Mambi Kabupaten Mamasa, data penyakit ISPA pada bulan januari-desember

2017didapatkan jumlah kasus ISPA untuk golongan umur balita (0-5 tahun) sebanyak 396 kasus.Dari 10 ibu yang memiliki balita penderita ISPA, 7 diantaranya memiliki pengetahuan kurang tentang penatalaksanaan ISPA, $2 \mathrm{ibu}$ memiliki pengetahuan cukup dan 1 ibu memliki pengetahuan baik.

Berdasarkan uraian di atas, maka peneliti bermaksud untuk mengetahui "Pengaruh pendidikan kesehatan dengan media leaflet terhadap pengetahuan ibu tentang penatalaksanaan ISPA pada balita di Puskesmas Mambi Kabupaten Mamasa".

melakukan penelitian. Rancangan penelitian secara umum mencakup dari identifikasi masalah hingga tehnik analisis data yang akan dilakukan. Secara khusus sering 
menyebut desain penelitian dengan makna jenis penelitian yang akan digunakan untuk mencapai tujuan penelitian. Desain penelitian yang dipilih akan membawa konsekuensi pada aturan desain tersebut. Oleh karena itu, pemilihan desain penelitian harus disesuaikan dengan tujuan yang ingin dicapai. Pemilihan desain penelitian yang tepat akan menentukan bobot penelitian yang akan dilakukan. Pemilihan desain harus disesuaikan dengan topik peneitian dengan memilih yang paling efesien dan dengan hasil yang memuaskan (Saryono, 2011).

Dalam penelitian ini, desain atau rancangan penelitian yang digunakan adalah Desain Pre Experimental dengan menggunakan rancangan One Group Pre-Test Post-Test Design. Dalam desain ini, cara pengukuran dilakukan satu kali pengukuran didepan (pre-test) sebelum adanya perlakuan (eksperimental treatment) dan setelah itu dilakukan pengukuran lagi (posttest).Perbedaan kedua hasil pengukuran di anggap sebagai efek perlakuan (Saryono, 2011).

\section{HASIL PENELITIAN DAN PEMBAHASAN}

\section{Hasil Penelitian}

\section{Analisa Univariat}

\section{Disribusi Responden Berdasarkan Umur Ibu}

Tabel 4.1

Karakteristik Responden Berdasarkan Umur Ibu

\begin{tabular}{|c|c|c|}
\hline \multicolumn{1}{|c|}{ Umur } & Frequency & Percent \\
\hline$<20$ Tahun & 3 & 15.0 \\
\hline $20-35$ Tahun & 15 & 75.0 \\
\hline$>35$ Tahun & 2 & 10.0 \\
\hline Total & 20 & 100.0 \\
\hline
\end{tabular}

Sumber : Data tahun 2018

Berdasarkan tabel diatas, 20-35 tahun (75\%), 3 responden menunjukkan bahwa dari 20 berumur $<20$ tahun $(15 \%)$ dan 2 responden, 15 responden berumur responden berumur $>35$ tahun $(10 \%)$. 
Disribusi Responden Berdasarkan Umur Balita

Tabel 4.2

Karakteristik Responden Bedasarkan Umur

Balita

\begin{tabular}{|c|c|c|}
\hline Umur & Frequency & Percent \\
\hline$<1$ Tahun & 3 & 15.0 \\
\hline 1-2 Tahun & 7 & 35.0 \\
\hline 3-5 Tahun & 10 & 50.0 \\
\hline Total & 20 & 100.0 \\
\hline
\end{tabular}

Sumber : Data tahun 2018

Berdasarkan tabel diatas, memiliki balita berumur 1-2 menunjukkan bahwa dari 20 responden, 10 responden memiliki balita berumur 3-5 tahun (35\%) dan 3 responden tahun $(50 \%), 7$ responden memiliki balita berumur $<1$ tahun (15\%).

Disribusi Responden Berdasarkan Tingkat Pendidikan Ibu

Tabel 4.3 Karakteristik Responden Berdasarkan Tingkat Pendidikan Ibu

\begin{tabular}{|c|c|c|}
\hline Tingkat Pendidikan & Frequency & Percent \\
\hline SD & 2 & 10.0 \\
\hline SMP & 5 & 25.0 \\
\hline SMA/SMK & 10 & 50.0 \\
\hline PT & 3 & 15.0 \\
\hline Total & 20 & 100.0 \\
\hline
\end{tabular}

Sumber : Data tahun 2018

Berdasarkan tabeldiatas, responden berpendidikan SMP menunjukkan bahwa dari 20 (25\%), 3 responden berpendidikan responden, $\quad 10 \quad$ responden PT $(15 \%)$ dan 2 responden berpendidikan SMA/SMK (50\%), 5 berpendidikan SD (10\%).

Disribusi Responden Berdasarkan Pekerjaan Ibu

Tabel 4.4 Karakteristik Responden Berdasarkan Pekerjaan Ibu

\begin{tabular}{|c|c|c|}
\hline Pekerjaan & Frequency & Percent \\
\hline Tidak Bekerja & 10 & 50.0 \\
\hline
\end{tabular}




\begin{tabular}{|c|c|c|}
\hline Bekerja & 10 & 50.0 \\
\hline Total & 20 & 100.0 \\
\hline
\end{tabular}

Sumber : Data tahun 2018

Berdasarkan tabel diatas, bekerja (50\%) dan 10 responden menunjukkan bahwa dari 20 bekerja (50\%). responden, 10 responden tidak

Disribusi Responden Berdasarkan Pengetahuan Ibu Sebelum Dilakukan Pendidikan Kesehatan Dengan Media Leaflet Tentang Penatalaksanaan ISPA Pada Balita

Tabel 4.5 Distribusi Frekuensi Pengetahuan Responden Sebelum Diberikan Pendidikan Kesehatan

\begin{tabular}{|c|c|c|}
\hline Kateori & Frequency & Percent \\
\hline Baik & 3 & 15.0 \\
\hline Cukup & 7 & 35.0 \\
\hline Kurang & 10 & 50.0 \\
\hline Total & 20 & 100.0 \\
\hline
\end{tabular}

Sumber: Data Tahun 2018

Berdasarkan tabel

diatas, menunjukkan bahwa

berpengetahuan kurang dari 20 responden sebelum (50\%), 7 berpengetahuan diberikan pendidikan cukup (35\%) dan 3 kesehatan, 10 responden berpengetahuan baik (15\%).

Disribusi Responden Berdasarkan Pengetahuan Ibu Setelah Dilakukan Pendidikan Kesehatan Dengan Media Leaflet Tentang Penatalaksanaan ISPA Pada Balita

Tabel 4.6 Distribusi Frekuensi Pengetahuan Responden Sesudah Diberikan Pendidikan Kesehatan

\begin{tabular}{|c|c|c|}
\hline Kategori & Frequency & Percent \\
\hline Baik & 13 & 65.0 \\
\hline Cukup & 7 & 35.0 \\
\hline Kurang & 0 & 0.0 \\
\hline Total & 20 & 100.0 \\
\hline
\end{tabular}

Sumber : Data Tahun 2018 
Berdasarkan tabel diatas, menunjukkan bahwa dari 20 responden setelah diberikan pendidikan kesehatan, 13 responden berpengetahuan baik (65\%), 7 berpengetahuan cukup (35\%) dan 0 berpengetahuan kurang (0\%).

\section{Analisa Bivariat}

Hasil pengolahan data responden sebelum dan sesudah dilakukan pendidikan kesehatan dengan media leflet terhadap pengetahuan ibu tentang penatalaksnaan ISPA pada balita dengan menggunakan bantuan program SPSS 21 dengan uji wilcoxonadalah sebagai berikut.

Tabel 4.7 Pengetahuan Ibu Sebelum dan Sesudah Pendidikan Kesehatan Dengan Media Leaflet Tentang Penatalaksanaan ISPA Pada Balita.

\begin{tabular}{|c|c|c|c|c|c|c|}
\hline & \multicolumn{3}{|c|}{ Post Test } & \multirow{2}{*}{ Total } & \multirow{2}{*}{ P-Value } \\
\hline & & Baik & Cukup & Kurang & & \\
\hline \multirow{6}{*}{ Pre Test } & Baik & 3 & 0 & 0 & 3 & \multirow{8}{*}{0.000} \\
\hline & $\%$ & $15.0 \%$ & $0.0 \%$ & $0.0 \%$ & $15.0 \%$ & \\
\hline & Cukup & 7 & 0 & 0 & 7 & \\
\hline & $\%$ & $35.0 \%$ & $0.0 \%$ & $0.0 \%$ & $35.0 \%$ & \\
\hline & Kurang & 3 & 7 & 0 & 10 & \\
\hline & $\%$ & $15.0 \%$ & $35.0 \%$ & $0.0 \%$ & $50.0 \%$ & \\
\hline \multicolumn{2}{|c|}{ Total } & 13 & 7 & 0 & 20 & \\
\hline \multicolumn{2}{|c|}{$\%$} & $65.0 \%$ & $35.0 \%$ & $0.0 \%$ & $100.0 \%$ & \\
\hline
\end{tabular}

Sumber: Data Tahun 2018

Dari hasil tabulasi silang di atas, didapatkan pengetahuan responden baik sebelum pendidikan kesehatan sebanyak 3 responden (15\%) dan setelah pendidikan kesehatan tetap baik 3 responden (15\%). Pengetahuan responden cukup sebelum pendidikan kesehatan sebanyak 7 responden
(35\%) dan sesudah pendidikan kesehatan berubah menjadi 7 baik (35\%). Sedangkan pada pengetahuan responden kurang sebelum pendidikan kesehatan sebanyak 10 responden (50\%) dan setelah pendidikan kesehatan berubah menjadi 7 baik (35\%) dan 3 cukup (15\%) dengan hasil uji 
statistikWilcoxon

didapatkan $p$-Value $=$ 0.000 ( $p \quad 0.000 \quad<0.05)$.

Dari hasil tersebut, dapat disimpulkan bahwa ada pengaruh yang signifikan terhadap perubahan tingkat pengetahuan ibu

\section{Pembahasan}

Berdasarkan

hasil penelitian yang didapatkan sebelum diberikan pendidikan kesehatan dengan media leaflet terhadap pengetahuan ibu tentang penatalaksanaan ISPA pada balita menunjukkan bahwa dari 20 responden, setengah dari responden memiliki pengetahuan yang kurang 50\% dan selebihnya responden berpengetahuan cukup 35\% dan baik $15 \%$. Peneliti berasumsi bahwa pengetahuan ibu kurang karena dipengaruhi oleh tingkat pendidikan ibu yang setengahnya berpendidikan SMA/SMK (50\%), Seperti yang kita ketahui bahwa pendidikan sangat penting untuk menunjang bertambahnya tingkat pengetahuan orang.Semakin tinggi tingkat pendidikan seseorang maka akan semakin berkualitas hidupnya (Hurlock, 2007). Kemudian ditinjau dari segi umur mayoritas responden berumur 20-35 tahun (75\%), dengan bertambahnya umur seseorang akan lebih menambah kematangan untuk berfikir dan kemampuan menangkap suatu sebelum dan sesudah pemberian pendidikan kesehatan dengan menggunakan media leaflet tentang penatalaksanaan ISPA pada balita $\left(\mathrm{H}_{0}\right.$ ditolak dan $\mathrm{H}_{1}$ Diterima).

informasi akan lebih mudah dan cepat.

Salah satu faktor yang mempengaruhi pengetahuan adalah tingkat pendidikan, dimana tingkat pendidikan yang lebih tinggi mempengaruhi persepsi seseorang untuk mengambil keputusan dan bertindak (Notoatmodjo, 2007). Seseorang dengan pendidikan tinggi akan cenderung untuk mendapatkan dan menerima informasi, baik dari orang lain maupun dari media massa lebih mudah dan banyak.

Disamping itu, umur dan pekerjaan juga mempengaruhi pengetahuan seseorang.Semakin bertambahnya usia maka kemampuan menerima informasi dan pola pikir seseorang semakin berkembang Notoatmodjo (2007),

Menurut Notoatmodjo (2007) dikatakan bahwa pekerjaan mempengaruhi pengetahuan.Seorang ibu rumah tangga lebih sering berinteraksi dengan keluarga dan banyak menghabiskan waktu di rumah dan hanya saat-saat tertentu para ibu rumah tangga bisa berinteraksi dengan orang 
banyak seperti saat arisan keluarga ataupun pengajian. Seharusnya akan banyak terpapar informasi dengan berbagi pengalaman kepada ibu rumah tangga yang lainnya tentang masalah kesehatan. Walaupun berada di rumah ibu rumah tangga bisa aktif mencari tahu tentang informasi kesehatan yang bisa di dapat melalui televisi ataupun majalah yang dapat meningkatakan pengetahuan untuk dapat mencegah penyakit, memelihara kesehatan dan dapat meningkatkan status kesehatan keluarga terutama untuk kesehatan balitanya.

Kemudian berdasarkan hasil yang didapatkan setelah diberikan pendidikan kesehatan dengan media leaflet terhadap pengetahuan ibu tentang penatalaksanaan ISPA pada balita menunjukkan bahwa dari 20 responden, sebagian besar responden sudah memiliki pengetahuan yang baik $65 \%$ dibandingkan dengan ibu yang berpengetahuan cukup $35 \%$ dankurang $0 \%$.

Salah satu upaya yang dapat dilakukan untuk meningkatkan pengetahuan ibu tentang Penatalaksanaan ISPA adalah dengan pemberian pendidikan

kesehatan.Peningkatan

pengetahuan ini sangat dibutuhkan oleh ibu agar dapat memahami

dalam penatalaksanaan dan pencegahan ISPA.Pendidikan kesehatan merupakan gambaran penting dan bagian dari peran perawat yang profesional dalam upaya promosi kesehatan dan pencegahan penyakit (preventif) (Fitriani, 2011).

Perilaku ibu menjadi sangat penting karena didalam merawat balitanya, ibu sering kali berperan sebagai pelaksana dan pengambil keputusan dan pengasuhan balita yaitu dalam hal memberikan makan, perawatan, kesehatan dan penyakit. Dengan demikian bila perilaku ibu baik dalam pengasuhan makanan dapat mencegah dan memberikan pertolongan pertama pada anak balita yang mengalami ISPA dengan baik (Silviana, 2014).

Dari hasil tabulasi silang yangdidapatkan, dapat dilihat bahwa terjadi suatu perubahan tingkat pengetahuan responden dari yang sebelunya berpengetahuankurang (50\%) menjadi cukup (15\%) dan baik (35\%), dari yang cukup (35\%) menjadi baik (35\%) dan yang baik tetap menjadi baik (15\%) setelah dilakukan pendidikan kesehatan dengan media leaflet terhadap pengetahuan ibu tentang penatalaksanaan ISPA pada balita di puskesmas Mambi Kabupaten Mamasa dengan hasil uji statistik Wilcoxon didapatkan $p$-Value $=0.000(p$ 0.000 <0.05). Dari hasil 
tersebut, dapat disimpulkan bahwa ada pengaruh yang signifikan terhadap perubahan tingkat pengetahuan ibu sebelum dan sesudah pemberian pendidikan kesehatan dengan menggunakan media leaflet tentang penatalaksanaan ISPA pada balita $\left(\mathrm{H}_{0}\right.$ ditolak dan $\mathrm{H}_{1}$ Diterima).

Pengetahuan menurut Notoatmodjo (2003) yang dikutip oleh (A. Wawan, 2010) dalam bukunya, pengetahuan merupakan hasil tahu dan hal ini terjadi setelah orang melakukan penginderaan terhadap sesuatu objek tertentu. Penginderaan terjadi melalui panca indera manusia, yaitu: indera penglihatan, pendengaran, penciuman, rasa dan raba. Pengetahuan (knowledge) adalah hasil tahu dari manusia terdiri dari sejumlah fakta dan teori yang memungkinkan seseorang untuk memecahkan masalah yang dihadapinya.

Berkaitan dengan usaha meningkatkan pengetahuan ibu tentang ISPA melalui pendidikan kesehatan, media pendidikan kesehatan sangat berperan penting karena media tersebut akan mempermudah penerimaan pesan kesehatan bagi masyarakat. Media pendidikan kesehatan adalah semua sarana atau upaya untuk menampilkan pesan informasi yang ingin disampaikan oleh komunikator sehingga sasaran dapat meningkat pengetahuannya yang akhirnya diharapkan dan berubah perilakunya kearah positif terhadap kesehatan (Ilmiah et al., 2017).

Hal ini sejalan dengan penelitian yang dilakukan oleh Tina Yuli Fatmawati 2016 tentang Pengaruh pendidikan kesehatan dengan Media Leaflet terhadap Pengetahuan Ibu tentang penatalaksanaan ISPA pada balita di Posyandu Bambu Kuning, didapatkan hasil sebelum dan sesudah diberikan pendidikan kesehatan diperoleh nilai $p$-value $=0,00<0,05$ dengan selisih nilai mean -2.35 . Hal ini menunjukkan ada pengaruh yang signifikan antara pengetahuan responden sebelum dengan setelah diberikan pendidikan kesehatan (Ilmiah et al., 2017).

Dalam penelitian ini diketahui bahwa pengetahuan responden sebelum diberikan pendidikan kesehatan masih rendah.Hal ini dapat dilihat dari gambaran jawaban sebelum pendidikan kesehatan.Setengah dari responden, pengetahuan responden masih kurang (50\%) dan setelah pendidikan kesehatan lebih banyak responden yang berpengetahuan baik $(65 \%)$ dan berpengetahuan kurang menjadi (0\%).Peneliti berasumsi karena sebagian besar ibu belum mendapatkan informasi tentang 
penatalaksanaan ISPA secara mendetail, sehingga ibu minim terhadap informasi dari luar sehingga perlu diadakan suatu kegiatan seperti pendidikan kesehatan guna untuk meningkatkan pengetahuan ibu terutama dalam peningkatan pengetahuan tentang penatalaksanaan ISPA pada balita dengan menggunakan media leaflet.

Tercapainya keluarga sehat yang dilandasi pengetahuan yang baik dapat menimbulkan kesadaran diri untuk memelihara lingkungan, mencegah penyakit dan mempertahankan kesehatan. Keluarga dapat menciptakan lingkungan yang sehat untuk anggota keluarganya sehingga dapat mencegah berbagai macam penyakit lingkungan erat

\section{PENUTUP}

\section{SIMPULAN DAN SARAN}

\section{Kesimpulan}

Berdasarkan hasil penelitian, dapat disimpulkan yaitu sebagai berikut :

Hasi lpenelitian yang didapatkan sebelum diberikan pendidikan kesehatan dengan media leaflet terhadap pengetahuan ibu tentang penatalaksanaan ISPA padabalita menunjukkan bahwa dari 20 responden, setengah dari responden

memiliki kaitannya dengan angka kejadian penyakit menular, terutama Infeksi Saluran Pernapasan Akut (ISPA) (Utari, Novayelinda, \& Arneliwati, 2011).

Dari hasil pembahasan diatas dapat dikatakan bahwa pemberian pendidikan kesehatan tentang penatalaksanaan ISPA terhadap ibu balita sangat berpengaruh dalam meningkatkan pengetahuan ibu tentang penatalaksanaan ISPA pada balita. Ini dapat dilihat dari perubahan pengetahuan ibu sebelum dan sesudah pendidikan kesehatan dengan menggunakan media leaflet tentang penatalaksanaan ISPA pada balita di Puskesmas Mambi Kabupaten Mamasa pengetahuan yang kurang 50\% dan selebihnya responden berpengetahuan cukup $35 \%$ dan baik $15 \%$.

Hasil penelitian yang didapatkan setelah diberikan pendidikan kesehatan dengan media leaflet terhadap pengetahuan ibu tentang penatalaksanaan ISPA pada balita menunjukkan bahwa dari 20 responden, sebagian besar responden sudah memiliki pengetahuan yang baik $65 \%$ dibandingkan dengan ibu yang berpengetahuan cukup 35\%, kurang sebanyak0\%. 
Dari hasil tabulasi silang, didapatkan pengetahuan responden baik sebelum pendidikan kesehatan sebanyak 3 responden (15\%) dan setelah pendidikan kesehatan tetap baik 3 responden (15\%). Pengetahuan responden cukup sebelum pendidikan kesehatan sebanyak 7 responden (35\%) dan sesudah pendidikan kesehatan berubah menjadi 7 baik $(35 \%)$. Sedangkan pada pengetahuan responden kurang sebelum pendidikan kesehatan sebanyak 10 responden (50\%) dan setelah pendidikan kesehatan berubah menjadi 7 baik $(35 \%)$ dan 3 cukup (15\%) dengan hasil uji Wilcoxon didapatkan $p$-Value $=0.000(p$ 0.000 <0.05). Dari hasil tersebut, dapat disimpulkan bahwa ada pengaruh yang signifikan terhadap perubahan tingkat pengetahuan ibu sebelum dan sesudah pemberian pendidikan kesehatan dengan menggunakan media leaflet tentang penatalaksanaan ISPA pada balita (Hoditolakdan $\mathrm{H}_{1}$ Diterima).

\section{Saran}

Bagi Puskesmas Mambi

Hasil penelitian ini diharapkan dapat menjadi masukan bagi tenaga kesehatan dalam menjalankan tugasnya khususnya dalam upaya peningkatan derajat kesehatan masyarakat dengan melaksanakan pendidikan kesehatan terutama dalam penanganan dan penatalaksanaan ISPA pada balita dengan menggunakan media leaflet.

BagiInstitusiPendidikan

Hasil penelitian ini diharapkan dapat menambah kepustakaan bagi pendidikan dalam menambah pengetahuan dan informasi mengenai penyakit ISPA khususnya dalam pendidikan kesehatan dengan menggunakan media leaflet terhadap pengetahuan ibu tentang penatalaksanaan ISPA pada balita.

BagiMasyarakat

Hasil penelitian ini diharapkan dapat memberikan informasi kepada masyarakat tentang pentingnya meningkatkan pengetahuan mengenai penyakit ISPA dengan mengikuti kegiatan pendidikan kesehatan dengan menggunakan media leaflet tentang penatalaksanaan ISPA pada balita, untuk meningkatkan pengetahuan, khususnya bagiibu yang memiliki balita agar tetapdapat mempertahankan dan menigkatkan derajat kesehatan.

BagiPeneliti

Hasil penelitian ini diharapkan dapat memberikan pengetahuan mengenai penyakit ISPA serta menambah pengetahuan tentang pengaruh pendidikan kesehatan dengan menggunakan media leaflet terhadap pengetahuan 
ibutentang penatalaksanaan ISPA pada balita.

BagiPeneliti Lain

Hasil penelitian ini diharapkan dapat menjadi sumber data dan informasi khususnya dalam melaksanakan penelitian lebih lanjut mengenai pengaruh

DAFTAR PUSTAKA

Dinkes Mamasa. (2016). Profil Kesehatan Kabupaten Mamasa Tahun 2016.

Dinkes Prov. Sulawesi Barat. (2016). Profil Kesehatan Tahun 2015.

Ilmiah, J., Batanghari, U., \& Vol, J. (2017). PENGARUH PENDIDIKAN KESEHATAN DENGAN MEDIA LEAFLET TERHADAP PENGETAHUAN IBU TENTANG PENATALAKSANAAN ISPA PADA BALITA DI POSYANDU Tina Yuli Fatmawati 1, 17(3), 227-234.

Junfeng, L., Zheng, C., \& Hengnian, L. (2015). [2 - 3], 37(2), 282286.

https://doi.org/10.6052/10000879-14-395

Kementerian Kesehatan RI. (2017).

Data dan Informasi Profil Kesehatan Indonesia 2016. Kementerian Kesehatan RI, 100. Retrieved from http://www.depkes.go.id/resour ces/download/pusdatin/lainlain/Data dan Informasi Kesehatan Profil Kesehatan Indonesia 2016 - smaller size web.pdf pendidikan kesehatan dengan media leaflet terhadap pengetahuan ibu tentang penatalaksanaan ISPA pada balita dengan menggunakan media pendidikan kesehatan lain seperti media video, flip chartdan lain sebagainya.

Silviana, I. (2014). Hubungan Pengetahuan Ibu Tentang Penyakit ISPA dengan Perilaku Pencegahan ISPA pada Balita Di PHPT Muara Angke Jakarta Utara Tahun 2014. Forum Ilmiah, 11(3), 402-411.

Utari, W., Novayelinda, R., \& Arneliwati. (2011). Efektifitas Pendidikan Kesehatan Terhadap Peningkatan Pengetahuan Keluarga Tentang Infeksi Saluran Pernapasan Akut (ISPA). Riau, 1-7. Retrieved from jom.unri.ac.id/index.php/JOMP SIK/article/download/3489/338 5

Dinkes Mamasa. (2016). Profil Kesehatan Kabupaten Mamasa Tahun 2016.

Dinkes Prov. Sulawesi Barat. (2016). Profil Kesehatan Tahun 2015.

Ilmiah, J., Batanghari, U., \& Vol, J. (2017). PENGARUH PENDIDIKAN KESEHATAN DENGAN MEDIA LEAFLET TERHADAP PENGETAHUAN IBU TENTANG PENATALAKSANAAN ISPA PADA BALITA DI POSYANDU Tina Yuli 
Fatmawati 1, 17(3), 227-234.

Junfeng, L., Zheng, C., \& Hengnian, L. (2015). [2 - 3], 37(2), 282286.

https://doi.org/10.6052/1000-

0879-14-395

Kementerian Kesehatan RI. (2017).

Data dan Informasi Profil

Kesehatan Indonesia 2016.

Kementerian Kesehatan RI, 100. Retrieved from http://www.depkes.go.id/resour ces/download/pusdatin/lain-

lain/Data dan Informasi

Kesehatan Profil Kesehatan

Indonesia 2016 - smaller size web.pdf

Silviana, I. (2014). Hubungan
Pengetahuan Ibu Tentang Penyakit ISPA dengan Perilaku Pencegahan ISPA pada Balita Di PHPT Muara Angke Jakarta Utara Tahun 2014. Forum Ilmiah, 11(3), 402-411.

Utari, W., Novayelinda, R., \& Arneliwati. (2011). Efektifitas Pendidikan Kesehatan Terhadap Peningkatan Pengetahuan Keluarga Tentang Infeksi Saluran Pernapasan Akut (ISPA). Riau, 1-7. Retrieved from jom.unri.ac.id/index.php/JOMP SIK/article/download/3489/338 5 